\author{
М.Д. Воейкова \\ ИЛИ РАН - СПбГУ \\ (Санкт-Петербург, Россия) \\ maria.voeikova@gmail.com
}

\title{
К ВОПРОСУ О МАРКИРОВАННОСТИ РУССКИХ ВИДОВЫХ ФОРМ В СОСЛАГАТЕЛЬНОМ НАКЛОНЕНИИ*
}

Семантическая нагруженность видовых форм глагола в изъявительном наклонении и в косвенных наклонениях распределяется по-разному: так, в императиве обычно немаркированный НСВ обрастает новыми семантическими оттенками (безотлагательность, близкое начало действия, категоричность и т.д.). Видовые характеристики глагола в сослагательном наклонении оказываются в сложной зависимости от других глагольных категорий. В статье рассматривается фактор акционального класса: характер действия, обозначенного глаголом, влияет на представление о его целостности в гипотетическом мире. Так, глаголы движения обычно встречаются в СВ в сослагательном наклонении, в то время как для местоположения характерно употребление обеих видовых форм, глаголы бытия и состояния естественно употребляются в форме $\mathrm{HCB}$, а для изменения состояния характерна форма СВ. Эти предпочтения отражаются на количественном соотношении форм $\mathrm{CB}$ и $\mathrm{HCB}$, а также на доле употреблений с семантическими сдвигами и проценте форм наиболее частотных глаголов в выборке. Употребление в несвойственной данному семантическому классу форме проявляется в многочисленных сдвигах значения, «непрототипических» употреблениях, неестественных контекстах. Эти предпочтения могут в разной степени проявляться в семантических группах, отличающихся по частотности и объему семантического класса.

Ключевые слова: морфология русского языка, вид глагола, сослагательное наклонение, маркированность, единичность/множественность, предельность, кратность, семантический класс глагола.

* Исследование выполнено за счет гранта Российского фонда фундаментальных исследований (проект 17-04-00 517-ОГН «Развитие морфологического и семантико-синтаксического компонентов корпусного описания грамматики современного русского языка») в ИЛИ РАН. 


\section{1. Полисистемный подход к вопросу выбора видовых форм}

В этой статье рассматривается взаимодействие категорий вида и наклонения с точки зрения «полисистемного подхода» к описанию русской грамматики. Описывая некоторый элемент этой грамматической системы, автор предполагает, что он связан с другими элементами и имеет сходное с ними строение, а результирующее описание способно представить систему в целом. В работах А.В. Бондарко этот подход, в частности, представлен как «полисистемный», ср. «... полисистемный анализ в сфере грамматики, в отличие от моносистемного, направлен на изучение единств, охватывающих как однородные, так и разнородные, разноуровневые (морфологические, словообразовательные, синтаксические, лексические) элементы в их многообразных сочетаниях. Цель такого анализа заключается прежде всего в изучении взаимосвязей элементов, которые не могут быть сведены к единому структурному основанию» [Бондарко 2011: 29]. В соответствии с этим подходом, мы будем рассматривать видовые соотношения в сослагательном наклонении на фоне аналогичных соотношений в изъявительном и повелительном наклонениях, предполагая, что такое целостное рассмотрение позволит в дальнейшем всесторонне представить взаимодействие категорий вида и наклонения в целом, а также прольет свет на особенности лексического и грамматического выбора видовых форм в речепорождении.

Нас интересуют прежде всего случаи «ненулевого» взаимодействия [Храковский 2012: 542], при котором реализация элементов одной грамматической категории оказывается хотя бы в какой-то степени ограниченной в контексте элементов другой грамматической категории, а также те примеры, когда содержание форм меняется в результате употребления в сочетании с другой категорией. Ненулевое взаимодействие вида и сослагательного наклонения зависит от синтаксической структуры, в которой появляются формы, и от внеязыковых условий — в данном случае от того, насколько говорящий склонен или способен представить себе гипотетическое действие в развертывании или повторе (формы НСВ), либо в форме, отражающей единичность и результативность (формы СВ). Н. Р. Добрушина перечисляет целый ряд независимых и зависимых структур, в которых встречается сослагательное наклонение [Добрушина 2016: 16-17]. Нас интересуют в первую очередь независимые структуры в двух основных функциях: сложные предложения, включающие формы сослагательного наклонения, могут передавать отношения условия (1), в простых предложениях сослагательное наклонение обычно выражает пожелание (2):

(1) Тебя бы подкормить, ты бы поздоровел. [Людмила Петрушевская. Маленькая волшебница // «Октябрь», 1996]

(2) — Ты бы посидел ещё полчаса на всякий случай. [Виктор Пелевин. Желтая стрела (1993)]

Интерес представляют все случаи, когда семантическое соотношение компонентов одной категории меняется вслед за изменением элементов другой категории. 
Для системного описания категории вида важен следующий факт: для форм изъявительного наклонения формы НСВ рассматриваются как немаркированный член привативной оппозиции, а формы CB — как маркированный член, обладающий дополнительным значением целостности и ограниченности действия пределом, ср. «В видовых формах заключено отношение к признакам ограниченности действия пределом и целостности: совершенный вид (CB) - семантически маркированная форма, являющаяся носителем этих признаков, несовершенный вид (НСВ) - немаркированный член оппозиции (в последующем изложении речь будет идти также о семантическом признаке «возникновение новой ситуации», связанном с большинством типов функционирования форм СВ» [Бондарко 2011: 30]. Неоднократно указывая на это соотношение видовых форм, А. В. Бондарко ссылается на мнение Ю. С. Маслова [1984: 15-16]. А. В. Бондарко далее отмечает, что «формы СВ, рассматриваемые со стороны их системного значения, характеризуются активным поведением по отношению к среде, тогда как формы НСВ демонстрируют поведение реактивное. Рассматриваемое различие связано со статусом маркированного и немаркированного членов оппозиции. Маркированность СВ определяет «сильное» (активное) воздействие грамматической системы на элементы среды, в то время как немаркированность НСВ создает разнообразные возможности для активного воздействия «сильной среды» на исходную систему. Немаркированность НСВ в отношении признаков «целостность» и «ограниченность действия пределом» играет роль своего рода пассивного фона, на который накладываются признаки внутрилексемной и внелексемной среды. Форма СВ выражает инвариантное значение, которое лишь конкретизируется и модифицируется контекстом (и шире - средой). Иной характер имеет семантический потенциал формы НСВ. Эта форма не имеет инвариантного положительного значения. Мы можем сказать лишь, что она обладает в грамматической системе некоторой значимостью, компетенцией, способностью выражать определенный спектр семантических признаков в составе частных видовых значений. Глагольная форма НСВ задает общие контуры и пределы этого спектра - от значений, контрастирующих с семантикой $\mathrm{CB}$, до значений, контактирующих с этой семантикой, хотя и не совпадающих с нею» [Бондарко 2011: 113-114].

\section{2. Вид в ирреальных наклонениях: история изучения}

Если принять употребление вида в индикативе за нулевое взаимодействие, то бесспорным случаем взаимодействия ненулевого следует считать многократно описанные дополнительные оттенки значения, которые формы НСВ приобретают в повелительном наклонении. Д.Н. Шмелев отмечал у форм НСВ в императиве, с одной стороны, черты, присущие НСВ в целом, например, употребление «для обозначения постоянного или повторного действия (мой руки перед едой = всегда)», а с другой стороны, добавочные значения: может значить не «вообще делай», а делай сейчас, скорее», т.е. обозначает побуждение к немедленному совершению действия; действие предельно приближено к моменту высказывания, как бы совпадает с ним; действие само по себе 
так или иначе уже предполагается (ожидается или естественно в данной ситуации); побуждение является только знаком для его начала, или условным вежливым приглашением [Шмелев 1959: 15-16]. Кроме этого, он выделяет спорный контекст, в котором «побуждение определяет, КАК должно исполняться действие» [Там же], по нашим данным, реализованный как в формах НСВ, так и в формах СВ.

В дальнейшем эти наблюдения были многократно уточнены и конкретизированы с разных точек зрения [Падучева 1996; Шатуновский 2004; Храковский 1988, Бенаккио 2010, см. обзор Воейкова 2015]. В результате сложилось представление о том, что НСВ в императиве обладает рядом дополнительных семантических функций, а его использование оказывается «нагруженным», отличающимся от нейтрального. Иными словами, при взаимодействии вида и наклонения в данном случае возникает «асимметрия» употреблений (термин Ю.А. Пупынина [Poupynin 2002: 18]).

Общая постановка задачи состоит в том, чтобы определить, относится ли взаимодействие вида и сослагательного наклонения к нулевому или ненулевому типу, то есть, реализуется ли при этом взаимодействии сценарий индикатива (нулевой тип, тривиальные соотношения видовых форм), или ненулевой тип (асимметричные отношения).

До сих пор этот вопрос во всей полноте не ставился, хотя отдельные ценные наблюдения делались во многих работах [Парменова 1975; Кулькова 1986; Подлесская 1999; Добрушина 2016; Храковский 2012; Шелякин 1983]. Так, В.С. Храковский указывает на деформацию в ирреалисе актуально-длительного значения, «от которого остается только его основная процессная составляющая. Кроме того, сокращается число неосновных частных значений обоих видов, которые могут выражаться в повелительном и сослагательном наклонении» [Храковский 2012: 561]. Тем самым подчеркивается асимметрия во взаимодействии вида и наклонения.

Помимо косвенных наклонений, для исследования данного вида взаимодействия оказываются релевантными правила употребления вида в инфинитиве при запретах или констатации невозможности (см. об этом [Шмелев А. Д. 2012: 610, Дымарский 2015], в которых также обнаруживается асимметрия: «Если слову нельзя подчинен инфинитив СВ, высказывание понимается алетически, а если инфинитив НСВ, - деонтически (ср. [Рассудова 1968: 82; Зализняк, Шмелев 2000: 41-42]). Так, предложение $K$ окну нельзя подойти скорее всего будет понято как указывающее на объективную невозможность (например, все подходы чем-то заставлены), а предложение $K$ окну нельзя подходить - как сообщение о существующем запрете» [Шмелев А. Д. 2012: 610]. Иными словами, контекст ирреалиса во многих случаях оказывает решающее влияние на интерпретацию видовых форм. Подробно влияние видовой характеристики на семантику высказывания рассматривалось также М.Я. Дымарским [2015] в контексте двух инфинитивных моделей с семантикой нежелательности: модели А (не опоздать бы к поезду) и модели Б (как бы нам не опоздать). Поскольку эти конструкции, несомненно, представляют собой периферию сослагательного наклонения, их учет представляется вполне оправданным. М. Я. Дымарский указывает на целый ряд факторов, влияющих на выбор вида 
инфинитива в данных конструкциях. Существенно, что видовая характеристика влияет на семантику конструкции А, но оказывается нерелевантной для истолкования модели Б: во многих случаях в ней можно заменить глагол СВ на глагол НСВ, ср. пример Дымарского: Как бы нам не зимовать/зазимовать здесь. Заметим, однако, что НСВ в этом случае вообще малоупотребителен и во многих случаях, кажется, невозможен, ср. модификацию исходного примера (?) Kaк бы нам не опаздывать на поезд. При том, что многие примеры с НСВ явно аграмматичны, вряд ли можно говорить о свободной конкуренции видов в этом случае. Как представляется, ирреалис в целом способствует выбору форм СВ, а для употребления НСВ требуются специальные условия. В модели А никакая замена невозможна; высказывания с НСВ выполняют функцию пожелания (ср. Не ссориться бы тебе с мужиками), а соответствующие высказывания с доминирующим в этом случае $\mathrm{CB}$ - функцию опасения, предостережения, ср. Не поссориться бы тебе с мужиками. Оставив в стороне детали истолкования и интерпретации видовой конкуренции, обратим внимание на то, что вид глагола влияет на семантику и на прагматику данной модели, причем СВ оказывается и здесь более употребительным и ожидаемым, чем НСВ, который в данном случае приобретает дополнительные оттенки значения. По-видимому, семантика совета или предостережения, характерная для этой конструкции, приближает ее в видовом отношении к императиву.

М.Я. Дымарский обращает внимание также на то, что на интерпретацию «контроптативных» моделей влияет их темпоральная направленность и персональная сфера. Он замечает, что при проспективно-консеквентной направленности высказывания и 1-м лице субъекта в модели А используется только СВ, а модель Б допускает оба вида инфинитива с семантикой опасения или даже предостережения [2015: 41-42] ср. его примеры: ... не убить бы чуткий интерес к писательским судьбам... (В.Кардин). При 2-м лице субъекта и проспективной направленности модель А допускает оба вида, но НСВ употребляется как совет, а СВ - как предостережение, ср. Не уходить бы вам... и Не обжечься бы тебе [Дымарский 2015: 43]. На роль персональности в видовой интерпретации сослагательного наклонения обращал внимание еще М.А. Шелякин. Он отмечал, что “функции видов при желательном значении зависят от синтаксической отнесенности действия ко 2-ому лицу или к 1-ому / 3-ему лицам ед. и мн. ч. При первой отнесенности видовые формы употребляются по правилам императивного употребления. При второй отнесенности выбор видов определяется в основном разовым / неразовым проявлением действия, а также характером выражения его отрицания. Если речь идет о разовом проявлении желательного действия или об опасении возможного осуществления разового действия, то употребляется форма сов. вида: Я бы в летчики пошел, пусть меня научат! (Маяковский). Пассажиры опасались, чтобы их самолет не задержался в пути. Если речь идет о неограниченно-продолжительных действиях (кратных и длительных) или об отрицании желательности разового действия, то употребляется форма несов. вида: - До чего же голосок у тебя хорош, бабка Игнатьевна! Век бы слушал и не наслушался! Не ел, не пил бы, а только заставлял бы тебя с утра до вечера покрикивать (Шолохов). Он не хотел, чтобы 
она уходила. [Шелякин 1983: 204-205]. Иными словами, по мнению М.А. Шелякина, выбор вида зависит не от наклонения, а от формы лица (естественно, что выбор наклонения отчасти и определяет отнесенность действия к определенному лицу). М.Я. Дымарский вслед за М.А. Шелякиным предлагает также рассматривать семантику контроптативных моделей раздельно в рамках каждой из возможных темпорально-персональных моделей. Такую практику можно назвать «расщеплением»: поскольку пока что не удается сформулировать общих закономерностей употребления форм во всех контроптативных конструкциях, можно попробовать рассмотреть отдельные выборки для каждой формы лица и времени и описать закономерности функционирования этих «расщепленных» выборок. Принимая во внимание предложенную М.А. Шелякиным гипотезу, мы в данной статье рассмотрим другой вариант ограничения материала: примеры будут разграничены по семантическим классам глаголов. При этом мы опираемся на семантическую разметку НКРЯ, отдавая себе отчет в том, что она во многих случаях не отличается высокой точностью. Мы будем во всех случаях вычитать из выборки часть примеров, попавшую в данный семантический класс по ошибке. Семантические группы глаголов были выбраны с таким расчетом, чтобы противопоставить предикаты, передающие максимальную активность субъекта (глаголы движения и активного воздействия) и его максимальную пассивность (глаголы существования и состояния). Остальные семантические классы привлекаются только для предварительной количественной оценки.

\section{3. Глаголы движения}

Контексты с глаголами движения рассматривались на примерах с двумя основными порядками компонентов: в первом случае бы предшествует глаголу (10 181 вхождение), а во втором следует за ним (более 34000 вхождений). Позиция субъекта специально не задавалась, но в подавляющем большинстве случаев он оказался перед глагольной группой. Препозиция частицы бы характерна для оптативных высказываний (3), в постпозиции бы чаще употребляется для выражения условных отношений (4).

(3) Да, пожалуй, в 60-е я бы переехал. [Юлия Пешкова. Пиковый козырь // «Домовой», 2002.01.04]

(4) Больший или меньший путь прошёл бы брусок, если бы этот опыт был поставлен на Луне? [Владимир Лукашик, Елена Иванова. Сборник задач по физике. 7-9 кл. (2003)

Разумеется, это не правило, а некоторая статистическая тенденция, причем подтвердить ее или опровергнуть на материале полученных десятков тысяч примеров пока не представляется возможным из-за их неоднородности. В том, что касается выбора видовых форм, большинство оптативных контекстов с глаголами движения типа (3) естественно включает форму СВ, которая несет информацию об однократном завершенном действии. Употребление НСВ в оптативе встречается редко 
и связано с семантикой временного отрезка, заполненного однотипными действиями, ср. (5):

(5) Лучше бы ходил всё Кино в настоящем обличии. [Коллективный форум: Блэйд (трилогия) Blade (2008-2010)]

Предпочтение СВ может быть связано с трудностями образования видовых пар у приставочных глаголов движения: как известно, часть этих глаголов при образовании имперфективов меняет однонаправленную основу на разнонаправленную (ср. прийти - приходить). Возможно, эта дополнительная сложность лежит в основе «избегания» форм НСВ от глаголов движения, обусловленном внеязыковыми причинами. В целом, в результате поиска глагола движения в претерите, стоящего после частицы $б ы$, на 8289 примеров с СВ приходится 2559 с НСВ. Можно заметить, что значительная часть примеров с НСВ по разным причинам не относится к каноническим случаям употребления сослагательного наклонения, подобным (34). Так, они могут быть на грани литературной нормы (ср. 6):

(6) Зарплата ничтожная, никого не привлекает. Берём кого попало, лишь бы шла. [И. Грекова. Перелом (1987)]

В примере (6) НСВ находится в отношениях свободного варьирования с СВ (ср.: лишь бы пошла); не назван контроллер для согласования в ж. р.. Часть примеров с НСВ включает дополнительные частицы, указывающие на гипотетическое сходство, ср. (7):

(7) Рассказывая о них, он как бы приступал к главному: рассказу о себе. [Василий Гроссман. Все течет (1955-1963) // «Октябрь», 1989]

Примеры с как бbl, словно бbl, будто бы естественным образом включают формы НСВ, но не относятся к основному массиву оптативных высказываний. Некоторая часть примеров содержит омонимичные формы, ошибочно истолкованные как НCB, ср. (8):

(8) «Только бы слетал и вернулся живым!» сказал Королев после старта ракеты-носителя. [Обобщенный календарь - апрель (2013.03.29) // «Новгородские ведомости»].

В других случаях глагол выступает в переносном значении, отличном от исходного значения перемещения. Это, в первую очередь, характерно для многочисленных контекстов с выражением следовало бы, но есть и другие примеры, ср. (9):

(9) Будь правительство политическим органом, отражающим интересы граждан, оно бы вело себя иначе. [Борис Вишневский. Квартрасплата // «Новая газета», 2003.01.16]

Учет этих факторов заставляет как минимум в три раза снизить количество употреблений сослагательного наклонения с НСВ у глаголов движения. Иными словами, глаголы движения в сослагательном наклонении примерно в 10 раз чаще встречаются в форме $\mathrm{CB}$, чем НСB. 


\section{4. Глаголы активного воздействия}

Ситуация с глаголами физического воздействия в количественном соотношении сходна с рассмотренными глаголами движения: на 2546 вхождений бы с глаголами СВ в постпозиции приходится 562 НСВ. Просмотрев все эти примеры, мы нашли среди НСВ 201 случай употребления перед бы частиц как, словно, будто, которые представляют собой отдельную частотную разновидность. Иными словами, и в этой группе примеров СВ примерно в 10 раз больше, чем «чистых» вхождений НCB. С учетом обратного порядка компонентов в общей сложности мы получили общую выборку из 6360 вхождений. Собственно «тривиальное» значение НСВ (повторяющееся или длящееся действие) выступает лишь в незначительной

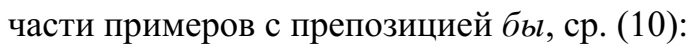

(10) - И хорошо, что эта Жанна увезла дочку. Тетя Регина ее бы била. [Маша Трауб. Нам выходить на следующей (2011)]

В два раза чаще и вполне в тривиальном значении НСВ встречается в контекстах, где частица бы следует за глаголом, как в (11):

(11) Мы вытирали бы ноги о список «Форбс», будь у нас хоть капля тщеславия. Но его нет - у нас другие потребности. [Виктор Пелевин. Бэтман Аполло (2013)]

Можно предположить, что препозиция по отношению к бы является существенным условием для употребления НСВ в сослагательном наклонении. Между тем, при таком порядке компонентов СВ все равно заметно чаще встречается (3774 CВ / 1080 НСВ). Это предпочтение можно объяснить внеязыковыми мотивами: говорящему более свойственно представлять себе завершенное и однократное следствие каких-либо воображаемых обстоятельств, чем выводить более сложную многократную закономерность. Потребность в таких далеко идущих предположениях в бытовой и художественной речи также ниже по сравнению с единичными следствиями или пожеланиями, ср. типичное высказывание с СВ (12):

(12) Был бы ты постарше, я бы ударил тебя тогда. [Василий Аксенов. Звездный билет // «Юность», 1961]

Пример (12) отличается еще и выраженной ретроспективной направленностью: речь идет о событии, которое уже состоялось и комментируется говорящим. Это проливает свет на специфику семантики СВ: часто речь идет не собственно о событии, а о его интерпретации, об оценке события, его изображении с помощью понятных носителю языка штрихов, как в (13):

(13) В последний раз посмотрел бы футбол, выпил бы пару кружек «Жигулевского» пива с сорожкой, обязательно поцеловал бы напоследок жену, накормил бы до отвала кошек их любимой килькой. [Эльвира Савкина. Если впрягаюсь, то основательно // «Дело» (Самара), 2002.05.03] 
Особая изобразительность $\mathrm{CB}$, характерная в изъявительном наклонении для наглядно-примерного значения будущего времени, вероятно, проявляется наиболее ярко в отрыве от обозначения реальных событий. Этой изобразительностью объясняется и утрированный выбор глаголов: 516 из 3774 вхождений глаголов СВ в претерите в препозиции к бы составляет глагол убить, как в примере (14):

(14) Если бы тогда увидел их, конечно, убил бы обоих. [А.И. Куприн. Гранатовый браслет (1911)]

На первый план в таких высказываниях часто выходит не информация о воображаемом событии, а анализ ментального или эмоционального состояния героя. Именно этим объясняется частотность формы убил бы, которая передает не истинные намерения говорящего, а его эмоциональный настрой или отношение к некоторым событиям. Как противоположность глаголам движения и физического воздействия рассматривались глаголы бытия и состояния, которым в целом свойственен НСВ.

\section{5. Бытийные глаголы}

Ожидаемое среди бытийных глаголов предпочтение НСВ (5336 HCВ/2470 СВ в позиции после $6 ы ; ; 71962$ НCВ/5813 СВ в препозиции к быl) оказывается на поверку объяснимо их огромным функциональным многообразием: в выборку попадают глаголы в бытийной (15a) и связочной (15б) функциях, так же как и временные показатели при модальных словах (15в):

(15a) - Если бы существовала маленькая вероятность кого-то спасти, я сделал бы всё, чтобы хотя бы кто-нибудь из моих детей остался в живых... [Эльвира Савкина. Если впрягаюсь, то основательно // «Дело» (Самара), 2002.05.03]

(15б) И я бы тебе этого не простил, если бы был твоим мужем. Моряки такого не прощают. Моряки знают, как поступать с такими девчонками. [Василий Аксенов. Пора, мой друг, пора (1963)]

(15в) И к Дарвину надо бы было по крайней мере отнестись повнимательней. [Фридрих Горенштейн. Куча (1982) // «Октябрь», 1996]

При всем этом функциональном многообразии между бытийными глаголами в разных функциях сохраняется семантическая преемственность и - что более важно - инерция их воспроизводства в определенной форме. Наибольшую частотность имеет среди них имеет глагол быть (4563 вхождения из всех 5336 после $\sigma b l)$. При такой частотности можно предположить, что формы этого глагола воспроизводятся в готовом виде, являются частью конструкции, а не избираются говорящим из парадигмы по каким-либо правилам. В этой группе мы имеем дело с ограниченным количеством глаголов в различных функциях.

Формы СВ от бытийных глаголов отличаются значительным лексическим разнообразием: в выборку разных бытийных глаголов в прош. вр. перед частицей бы 
вошли и глаголы исчезновения-появления, и частично - глаголы физического воздействия (типа того же убить, являющегося каузатором прекращения существования). Собственно бытийных контекстов среди них выделено 1557, включая различные приставочные корреляты глагола жить (типа прожить, дожить, выжить), но и группа глаголов, относящихся к событиям типа состояться, сложиться, случиться, произойти. Таким образом, СВ бытийных глаголов представлен в двух разновидностях - длительно-ограничительной (16а) или событийной (16б):

(16а) Если бы не Николас, она, по уверениям врачей, не прожила бы и 2 дней. [Анна Маева. Дар на всю жизнь // «Здоровье», 1999.03.15]

(16б) - Да не переживай ты, Даня, не казнись, поздно или рано это неизбежно произошло бы. [Виктор Астафьев. Пролетный гусь (2000)]

И в том, и в другом случае речь идет о перифразе бытийного предложения: прожила 2 дня в (16а) означает 'существовала еще 2 дня', произошло в (16б) означает 'было’, однако можно ли такие перифразы считать каноническим выражением семантики существования, остается дискуссионным вопросом. Если да, то следует признать, что мы понимаем бытийные предикаты предельно широко в соответствии с точкой зрения Н. Ю. Шведовой [1989: 5-12], которая включала в предикаты существования все глаголы, обозначающие привычный способ проявления объектов. При такой трактовке не соблюдается правило мены им. падежа на родительный при отрицании, характерное для бытийных предикатов, ср. (16а) и каноническое отрицательное бытийно-локативное предложение: её не было два дня. Следовательно, в ситуации с бытийными глаголами СВ встречается обычно не у центральных, а у периферийных бытийных глаголов, которые только в определенной форме (а именно в прош. времени) выражают семантику существования попутно с ядерной семантикой, а большинство канонических бытийных глаголов в сослагательном наклонении (так же как и в изъявительном) чаще используются в HCB.

\section{6. Глаголы состояния и изменения состояния}

Анализ группы глаголов с семантикой изменения состояния - это единственная возможность в корпусе «подобраться» к глаголам состояния, которые почемуто не попали в отдельную строку семантической разметки. Можно только предположить, что канонические глаголы состояния (такие как cnamb, cuдеть, лежать и т. д. ) склонны к преимущественному употреблению в НСВ во всех наклонениях. Об этом свидетельствуют результаты поиска по отдельным глаголам: так, для формы сnал бы зафиксировано 123 вхождения, в то время как посnал бы встречается 13 раз, проспал бы 29 раз, а переспал бы всего 2 раза. Существенно при этом, что все приставочные глаголы СВ имеют специфические оттенки значения (ср. переcnaл) и закрепляются, «специализируются» на них. Так, у глагола просыnamb/npocnamb выделяют три основных значения: «1) спать в течение какого-то времени..., 
2) встать после сна позже, чем обычно, чем нужно... и 3) находясь в состоянии сна, уснув, пропустить что-либо...» [ССРЛЯ 1961: 1423]. Второе значение выделено исключительно на основе непереходности. Если бы не нужно было ее учитывать, оно вполне соответствовало бы третьему. Среди 29 вхождений глагола проспать в нашей выборке 17 соответствуют первому значению и 12 - третьему, т. е. содержат отрицательную коннотацию ('проспать больше, чем нужно, иногда пропуская нечто важное'). Диахронически третье значение кажется более современным, т. к. его доля растет с течением времени. Разумеется, небольшое количество примеров не позволяет сделать однозначный вывод, однако тенденция очевидна: СВ от канонических глаголов состояния встречается заметно реже НСВ и стремится закрепиться в специальных, производных от основного значениях. Добавив глаголы состояния к разметке НКРЯ, мы сможем получить более исчерпывающие данные об этом процессе.

По имеющимся данным можно заметить, что для глаголов изменения состояния, которые в разметке НКРЯ все же присутствуют, хотя не отделены от собственно состояния, ожидаемо предпочтительным оказывается СВ: это неудивительно, так как изменение состояния - один из категориальных признаков СВ. На 2331 вхождение глаголов СВ в сослагательном наклонении в препозиции к частице бы приходится 289 глаголов НСВ. При этом глаголы СВ практически во всех примерах выступают в прямом основном значении, ср. (17):

(17) Пусть на 10 минут, но дольше. Значит, и замерз бы раньше. [Андрей Митьков. Юрий Кудинов, чемпион Европы-2002 // «Известия», 2002.07.26]

Как и у глаголов физического воздействия, в этой семантической группе повествование о возможном единичном событии значительно более естественно и вероятно, чем рассказ о гипотетической цепочке событий или о гипотетическом развертывании действия во времени, ср. (18):

— В те часы, когда ты бы спал, ты не сомкнешь глаз. В те минуты, когда пот высыхал бы у тебя на висках, твоя спина покроется кровью от напряжения. [Ирина Краева. Тим и Дан, или Тайна «Разбитой коленки»: сказочная повесть (2007)]

В примере (18) НСВ сочетается с СВ в изъявительном наклонении (не сомкнешь, покроется), что следует отнести к авторским особенностям речи, отчего все высказывание производит неестественное впечатление. 2\% в выборке составляют омонимы других частей речи или омонимичные глаголы типа кисло бbl, cneло бbl, добрела бbl, ошибочно попавшие в глаголы состояния вне своего контекста. Это, на первый взгляд, случайное обстоятельство, на самом деле, является характерной чертой «непредпочтительных» видовых форм: в выборке без снятия омонимии обычно именно среди таких форм встречаются многочисленные нарушения и большой процент «мусора» и ошибочных примеров. Соотношение верных и случайных примеров в разных семантических группах рассматривается в следующем разделе. 


\section{7. Количественные показатели остальных групा}

В каждой из семантических групп глаголов один вид соответствует лексическому значению группы и встречается значительно (иногда в 10 раз) чаще другого. Таблица 1 показывает соотношение форм СВ/НСВ у глаголов различных семантических групп и другие количественные особенности выборок.

Таблицса 1

Доля СВ, процент «мусора» и доля частотных глаголов в выборке (предварительный анализ)

\begin{tabular}{|l|c|c|c|c|}
\hline Семантический класс & Количество вхождений & \% СВ & \% ошибок в СВ & $\begin{array}{c}\text { \% частотных } \\
\text { глаголов в СВ }\end{array}$ \\
\hline Активное действие & 7962 & 79 & 20 & 13 \\
\hline Движение & 44192 & 76 & 33 & 0 \\
\hline Существование & 77298 & 18 & 38 & 84 \\
\hline Изменение сост. & 4216 & 89 & 12 & 2 \\
\hline Поведение & 143 & 32 & 8 & 15 \\
\hline Местоположение & 9701 & 66 & 48 & 56 \\
\hline Речь & 12924 & 88 & 9 & 12 \\
\hline Физиолог. Реакции & 1643 & 48 & 9 & 11 \\
\hline Ментальное действие & 17935 & 22 & 26 & \\
\hline
\end{tabular}

Разумеется, подсчеты, вошедшие в таблицу 1, имеют предварительный характер. В многочисленных группах глаголов доля СВ и процент ошибочных и частотных глаголов подсчитывались как среднее по нескольким образцам по 100 примеров из рандомной выборки. Однако даже такой предварительный анализ показывает некоторые тенденции. Предсказуемо у глаголов активного действия, движения, изменения состояния наблюдается предпочтение форм СВ в сослагательном наклонении, в то время как у глаголов существования, поведения или ментального действия преобладают формы НСВ. Высокий процент СВ среди глаголов речи объясняется тем, что половину из них составляют разные формы глагола сказать. Для некоторых групп оказался очень высоким процент ошибочных форм и употреблений. Так, в группу глаголов местонахождения попали многочисленные употребления глаголов, с местонахождением никак не связанные, типа оставили в покое, остался в стороне и т. д. В результате этого количественное соотношение $\mathrm{CB} / \mathrm{HCB}$ в этой группе почти равное, $\mathrm{CB}$ даже преобладает, однако в НСВ фактически все примеры соответствуют базовому значению, при том что почти половина из всей выборки СВ оказалась ошибочной. Это указывает на то, что СВ оказывается менее естественной формой для глаголов местонахождения. В целом, эти предварительные подсчеты нуждаются в усовершенствовании и уточнении, однако уже по первичному анализу можно судить о том, что говорящий, скорее всего, не производит серьезного выбора форм, а следует неким образцам, клишированным употреблениям, представление о которых содержится в его языковой памяти. 


\section{8. Заключение}

Анализ соотношения видовых форм у глаголов разных семантических групп показывает, что употребление вида в сослагательном наклонении в тривиальных случаях семантически соотносится с изъявительным: формы НСВ представляют действие в процессе развертывания или как повторяющееся. Однако назвать формы НСВ немаркированными в сослагательном наклонении довольно трудно нельзя сказать, чтобы они употреблялись чаще или «по умолчанию», напротив, во многих семантических классах для выбора форм НСВ необходимы существенные контекстуальные условия.

Процентное соотношение и интерпретация видовых форм сослагательного наклонения зависит от акционального класса глагола. В большинстве акциональных классов наблюдается предрасположенность к употреблению в форме СВ или НСВ в соответствии с характером действия - его активностью/пассивностью, особенностями протекания, способностью говорящего гипотетически представить это действие как однократное и завершенное или как многократное или захваченное в серединной стадии своего осуществления. Эта предрасположенность выражается в том, что преферентная видовая форма менее зависит от контекста, значительно (иногда в 10 раз) чаще встречается, в выборке примеров с этой формой наблюдается мало ошибок и отклонений от основного значения глагольной группы. Важно также обращать внимание на то, насколько многочисленна сама семантическая группа глаголов: некоторые группы (такие как экзистенциальные глаголы) немногочисленны и их свойства определяются поведением самых частотных лексем.

Перспективным представляется дальнейший учет взаимодействия категорий вида и наклонения с категорией лица глагола: можно предположить, что формы 1-го л. будут отличаться от форм 2-го и 3-го л. с точки зрения интерпретации самого гипотетического действия.

\section{Литература}

Бенаккио Р. Вид и категория вежливости в славянском императиве. МюнхенБерлин: Отто Загнер, 2010.

Бирюлин Л. А. Семантика и прагматика русского императива. Хельсинки: Изд-во Хельсинского ун-та, 1994.

Бондарко А. В. Категоризация семантики. М.: ЯСК, 2011.

Воейкова М.Д. Варьирование форм СВ/НСВ в императиве: анализ факторов // Acta Linguistica Petropolitana. Труды Института лингвистических исследований. 2015. T. XI. №1. C. 539-565. https://alp.iling.spb.ru/static/alp_XI_1.pdf

Добрушина Н.P. Сослагательное наклонение в русском языке: опыт исследования семантики. Прага: Animedia company, 2016.

Дымарский М. Я. Инфинитивные высказывания с семантикой нежелательности: вид, время, лицо, типовые значения. Вопросы языкознания. 2015. № 5. С. 26-48. 
Кулькова Р. А. Функционирование сослагательного наклонения в современном русском языке. Автореф. дис. канд. филол. наук. М.: МГУ, 1986.

Падучева E.B. Семантика и прагматика несовершенного вида императива // Е. В. Падучева. Семантические исследования: Семантика времени и вида в русском языке. Семантика нарратива. М.: Языки русской культуры, 1996. С. 66-83.

Парменова Т.В. Функционирование сослагательного наклонения в современном русском языке. Автореф. дис. ... канд. филол. наук. Л.: ЛГПИ им. А. И. Герцена, 1975.

Подлесская В.И. Условные конструкции: стратегии кодирования и функциональная мотивация // Тестелец Я. Г., Рахилина Е. В. (ред.) Типология и теория языка: от описания к объяснению (к 60-летию А.Е. Кибрика). М.: ЯРК, 1999. С. 255273

Пупынин Ю. А. Системные связи грамматических категорий глагольного предиката в современном русском языке. Дис. ... докт. филол. наук. СПб., 1992.

Пупьлин Ю.А. Грамматические категории русского глагола в их системно-парадигматических и функциональных связях // Бондарко А. В. (ред.) Межкатегориальные связи в грамматике. СПб.: Дмитрий Буланин, 1996.

ССРЛЯ - Словарь современного русского литературного языка. Т. 11. М.-Л.: Изд-во АН СССР, 1961.

Храковский В. С. Императивные формы НСВ и СВ в русском языке и их употребление // Russian Linguistics. 1988. 12, 3. Р. 269-292.

Храковский В.C. Взаимодействие грамматических категорий глагола. Опыт анализа // Вопросы языкознания. 1990. № 5. С. 18-36.

Храковский В. С. Грамматические категории глагола (опыт теории взаимодействия) // А. В. Бондарко (ред.). Межкатегориальные связи в грамматике. СПб.: Дмитрий Буланин, 1996. С. 22-42.

Храковский В.С. Взаимодействие грамматических категорий: вид, время, наклонение // М.Д. Воейкова (ред.). От значения к форме, от формы к значению. Сборник статей в честь 80- летия члена-корреспондента РАН А. В. Бондарко. М.: Языки славянской культуры, 2012. С. 539-561.

Шатуновский И. Б. Императив и вид // М. Ю. Черткова (ред.). Труды аспектологического семинара филологического факультета МГУ им. М. В. Ломоносова. Т. 4. М.: Макс Пресс, 2004. С. 253-280.

Шведова Н. Ю. Русские бытийные глаголы и их субъекты // Шведова Н. Ю., Лопатин В.В. (ред.) Слово и грамматические законы языка: глагол. М.: Наука, 1989. C. 5-171.

Шмелев Д.Н. О значении вида в повелительном наклонении // Русский язык в школе. 1959. 20, 4. С. 13-17.

Шмелев А.Д. Модальность, контроль и вид: точки взаимодействия (русское слово нельзя в сочетании с инфинитивом) // М.Д. Воейкова (ред.). От значения к форме, от формы к значению. Сборник статей в честь 80-летия члена-корреспондента РАН А. В. Бондарко. М.: Языки славянской культуры, 2012. 
Poupynin Yu.A. The category of voice in connection with other grammatical categories in Russian» GUSLI Working Papers of the Department of Slavic Languages, University of Goeteborg. 2002. No. 12.

Poupynin Yu.A. Interaction between Aspect and Voice in Russian. MünchenNewcastle: LINCOM Studies, 1999.

\author{
Maria D. Voeikova \\ ILS RAS - SPbSU \\ (Saint Petersburg, Russia) \\ maria.voeikova@gmail.com
}

\title{
ON THE MARKEDNESS OF RUSSIAN ASPECTUAL FORMS IN SUBJUNCTIVE
}

The semantic load of Russian aspectual forms in the indicative and in the imperative mood is distributed differently: while in the indicative the imperfective is considered to be an unmarked default form, in the imperative it acquires a range of extra semantic nuances, being more categorical, expressing that the action required should happen soon and may not be postponed, and signaling that the action is expected in a given situation or was discussed before. The aspectual characteristics of Russian verbs in the subjunctive depend on several factors and other verb categories. The article discusses one of those categories, namely, the Aktionsart of verbs. The nature of the hypothetical action has an impact on its verbal presentation in terms of its telicity. Thus, verbs of motion or change of state tend to be used in the perfective form, verbs of localization do not show any preference, whereas verbs of existence or state prefer the imperfective forms. These preferences are manifested not only in the percentage of certain forms but also by their semantic homogeneity and by the percentage of the most frequent verbs in the resulting sample. Numerous semantic shifts, and their use in non-prototypical meanings and in unnatural contexts are also characteristics of the non-preferred use of aspectual forms. The grade of aspectual preferences differs for semantic classes depending on their frequency and on the number of verbs in each class.

Keywords: Russian morphology, verbal aspect, subjunctive mood, markedness, singularity/plurality of action, telicity, limitativity, semantic class.

\section{References}

Benakkio R. Vid i kategoriya vezhlivosti v slavyanskom imperative [Aspect and the category of politeness in the Slavic imperative]. München-Berlin: Verlag Otto Sagner, 2010. (In Russ.)

Biryulin L. A. Semantika i pragmatika russkogo imperativa [Semantics and pragmatics of the Russian imperative]. Helsinki: Univ. of Helsinki, 1994. (In Russ.) 
Bondarko A.V. Kategorizaciya semantiki [Categorisation of semantics]. Moscow, «YaSK» Publ., 2011. (In Russ.)

Dobrushina N.R. Soslagatel'noe naklonenie v russkom yazyke: opyt issledovaniya semantiki [Subjunctive mood in Russian: the study of semantics]. Praga, «Animedia company», 2016. (In Russ.)

Dymarskij M.Ya. Infinitivnye vyskazyvaniya s semantikoj nezhelatel'nosti: vid, vremya, lico, tipovye znacheniya [Infinitive sentences with the counteroptative semantics: aspect, tense, mood and typical meanings]. Voprosy jazykoznanija, 2015, no. 5, pp. 2648. (In Russ.)

Khrakovskij V. S. Imperativnye formy NSV i SV v russkom yazyke i ih upotreblenie [Imperative forms of imperfective and perfective aspect in Russian and their use] // Russian Linguistics. 1988, 12, 3, pp. 269-292. (In Russ.)

Khrakovskij V.S. Vzaimodejstvie grammaticheskih kategorij glagola. Opyt analiza [Interaction of grammatical categories of Russian verb: an attempt of analysis] // Voprosy jazykoznanija. 1990, no. 5, pp. 18-36. (In Russ.)

Khrakovskij V.S. Grammaticheskie kategorii glagola (opyt teorii vzaimodejstviya) // A.V. Bondarko (ed.). Mezhkategorial'nye svyazi v grammatike [Intercategorial connections in grammar]. St. Petersburg, 1996, pp. 22-42. (In Russ.)

Khrakovskij V.S. Vzaimodejstvie grammaticheskih kategorij: vid, vremya, naklonenie // M. D. Voejkova (ed.). Ot znacheniya kforme, ot formy k znacheniyu. Sbornik statej $v$ chest' 80 - letiya chlena-korrespondenta RAN A. V. Bondarko. Moscow, «Yazyki slavyanskoj kul'tury» Publ., 2012, pp. 539-561. (In Russ.)

Kul'kova R. A. Funkcionirovanie soslagatel'nogo nakloneniya $v$ sovremennom russkom yazyke [Functionning of the subjunctive mood in modern Russian. Referat of the dissertation]. Avtoref. dis. kand. filol. nauk. Moscow, MGU, 1986. (In Russ.)

Paducheva E. V. Semantika i pragmatika nesovershennogo vida imperativa [Semantics and pragmatics of the imperfective imperative in Russian] // E. V. Paducheva. Semanticheskie issledovaniya: Semantika vremeni $i$ vida v russkom yazyke. Semantika narrativa [Semantic studies: semantics of aspect and tense in Russian. Semantics of narrative]. Moscow, «Yazyki russkoj kul'tury» Publ., 1996, pp. 66-83. (In Russ.)

Parmenova T.V. Funkcionirovanie soslagatel'nogo nakloneniya $v$ sovremennom russkom yazyke [Functionning of the subjunctive in modern Russian. Referat of the dissertation]. Avtoref. dis. kand. filol. nauk. L., LGPI im. A. I. Gercena, 1975. (In Russ.)

Podlesskaya V.I. Uslovnye konstrukcii: strategii kodirovaniya i funkcional'naya motivaciya [Causative constructions: strategies of the coding and functional motivation] // Testelets Ya.G., Rakhilina E.V. (eds.) Tipologiya i teoriya yazyka: ot opisaniya k ob»yasneniyu (k 60-letiyu A.E. Kibrika) [Language typology and language theory: from description to explanation. For the 60th anniversary of A.E. Kibrik]. Moscow, «YaRK» Publ., 1999, pp. 255-273. (In Russ.)

Pupynin Yu.A. Sistemnye svyazi grammaticheskih kategorij glagol'nogo predikata $v$ sovremennom russkom yazyke [Systemic relations of grammatical categories of the verb predicate in modern Russian]. Unpublished doctoral dissertation. Dis. ... d.f.n. St. Petersburg, 1992. (In Russ.) 
Pupynin Yu.A. Grammaticheskie kategorii russkogo glagola v ih sistemno-paradigmaticheskih i funkcional'nyh svyazyah [Grammatical categories of Russian verb in its systemic paradigmatic and functional relations] // Bondarko A. V. (ed.) Mezhkategorial'nye svyazi v grammatike [Intercategorial connections in grammar]. St. Petersburg, 1996. (In Russ.)

Poupynin Yu. A. The category of voice in connection with other grammatical categories in Russian». GUSLI Working Papers of the Department of Slavic Languages, University of Goeteborg, 2002, no. 12.

Poupynin Yu. A. Interaction between Aspect and Voice in Russian. München-Newcastle: LINCOM Studies, 1999.

SSRLJa - Slovar' sovremennogo russkogo literaturnogo jazyka [Dictionary of Modern Russian Literary Language]. V. 11. M.-L., AN SSSR, 1961. (In Russ.)

Shatunovskij I. B. Imperativ i vid [Imperative and aspect] // M. Yu. Chertkova (red.). Trudy aspektologicheskogo seminara filologicheskogo fakul'teta MGU im. M.V. Lomonosova. V. 4. Moscow, «Maks Press» Publ., 2004, pp. 253-280. (In Russ.)

Shmelev D.N. O znachenii vida v povelitel'nom naklonenii [On semantics of aspect in the imperative] // Russkij yazyk v shkole. 1959, 20, 4, pp. 13-17. (In Russ.)

Shmelev A.D. Modal'nost', kontrol' i vid: tochki vzaimodeǐstviya (russkoe slovo nel'zya $\mathrm{v}$ sochetanii $\mathrm{s}$ infinitivom) [Modality control and aspect: points of interconnestions] // M. D. Voejkova (red.). Ot znacheniya $k$ forme, ot formy $k$ znacheniyu. Sbornik statej $v$ chest' 80- letiya chlena-korrespondenta RAN A. V. Bondarko [From meaning to form and from form to meaning] Moscow, «Yazyki slavyanskoj kul'tury» Publ., 2012. (In Russ.)

Shvedova N. Ju. Russkie bytiynye glagoly i ix subjekty [Russian existential verbs and their subjects] // Shvedova N. Ju., Lopatin V.V. (eds.) Slovo i grammaticheskie zakony jazyka: Glagol. Moscow, «Nauka» Publ., 1989, pp. 5-171. (In Russ.)

Voejkova M.D. Var'irovanie form SV/NSV v imperative: analiz faktorov [Variation of the perfective / imperfective forms in the imperative: the analysis of factors] // Acta Linguistica Petropolitana. Trudy Instituta lingvisticheskih issledovanij, 2015. V. XI, no. 1, pp. 539-565. https://alp.iling.spb.ru/static/alp_XI_1.pdf (In Russ.) 